\title{
PRESENÇA DE DANTE NA OBRA DE MACHADO DE ASSIS
}

\author{
Jean-Michel Massa \\ In memoriam
}

\author{
APRESENTAÇÃO E TRADUÇÃO \\ Eugênio Vinci de Moraes \\ Centro Universitário Uninter, Curitiba, Paraná, Brasil \\ Maria Adriana Camargo Cappello \\ Universidade Federal do Paraná, Curitiba, Paraná, Brasil
}

Este "La présence de Dante dans l'oeuvre de Machado de Assis", escrito por Jean-Michel Massa, é fruto de uma comunicação feita por ele no VII Congresso Nacional da Société Française de Littérature Comparée, em 1965. Um ano mais tarde foi transformada em texto e publicada no volume Études luso-brésiliennes, organizado por Jean François Botrel, Armelle Le Bars-Poupet e pelo próprio Massa (Paris: PUF, 1966). Há um exemplar desse livro na biblioteca do Instituto de Estudos Brasileiros, da USP, que nos cedeu a cópia, pelo que agradecemos.

O texto fez parte das homenagens a Dante pelos setecentos anos de seu nascimento (neste ano de 2015 comemoram-se 750). Como grande estudioso de Machado, Massa aproveitou a ocasião para procurar compreender a presença de Dante na obra do autor de Esaú e Jacó. É o mesmo ano em que se publica no Brasil o caderno do Suplemento Literário de $O$ Estado de S. Paulo, dedicado a Dante e organizado por Edoardo Bizarri, tradutor de Guimarães Rosa para o italiano. São dois textos seminais para os estudos sobre a relação entre a obra de Dante e Machado de Assis, que se somam ao de Mário de Andrade, em que o modernista compara o poema "Última jornada", de Americanas, ao canto V do "Inferno".

Massa levanta neste artigo algumas hipóteses acerca das escolhas de Machado em relação à obra de Dante. Comenta, por exemplo, que a tradução do canto XXV do "Inferno" pode ser uma homenagem do brasileiro à Beleza, sentimento que teria sido despertado por seu contato com a poesia parnasiana.

Este texto está mencionado na Bibliografia Machadiana (número 833), organizada por Ubiratan Machado, e, até onde sabemos, ainda não havia sido traduzido para o português, o que fazemos agora em homenagem a Jean-Michel Massa e aos 750 anos do nascimento de Dante. 


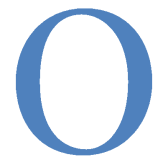

s estudos consagrados ao contato entre o domínio literário italiano e o luso-brasileiro são ainda bem pouco numerosos. Entretanto, a influência da literatura italiana não deixou de se difundir por Portugal ou pelo Brasil, sobretudo em alguns de seus momentos privilegiados, quando tudo e todos se italianizavam - durante o Renascimento, por exemplo. Sendo assim, grandes escritores italianos, com suas respectivas fortunas críticas - Dante, Petrarca, Machiavel, Goldoni, Metastasio, Alfieri, Leopardi etc. -, foram lidos tanto em Portugal como no Brasil. Não faz parte de nossos objetivos abordar todo esse vasto campo de discussão, nem mesmo buscar explicar o relativo silêncio da crítica a respeito. Indiquemos apenas uma das razões de tal negligência. A difusão da literatura francesa, mais vistosa, e com presença mais constante, talvez tenha, em parte, mascarado essa influência italiana. A floresta não nos deve fazer esquecer as árvores.

Uma justa reviravolta do acaso, no entanto, fez recair sobre um francês o papel de fornecer alguns pormenores da influência exercida por um escritor italiano sobre o brasileiro Machado de Assis. Tentativa na qual podemos ver, ainda, o desejo de um italianista em se associar à homenagem prestada neste ano a Dante por ocasião do sétimo centenário de seu nascimento.

Para além da oportunidade que uma efeméride oferece, não se trata de uma união gratuita desses dois nomes. Com efeito, Machado de Assis é, sem dúvida, o maior escritor brasileiro; um dos poucos que, guardadas todas as suscetibilidades nacionais, está à altura de Dante.

Como esse autor é ainda pouco conhecido e, portanto, pouco apreciado - a não ser pelos falantes de língua portuguesa -, faz-se necessário, a fim de bem situar nosso propósito, indicar brevemente algumas das razões que o tornam tão eminente nas literaturas da América do Sul. Por outro lado, é preciso indicar por que motivos ele é uma escolha interessante para um comparatista.

Sua obra se desenvolve durante dois períodos capitais da história literária e, mesmo, da própria história do Brasil. Machado de Assis, nascido em 1839, começa a escrever em 1855 e, até sua morte, em 1908, nunca deixou de publicar. Ele viveu, portanto, o Brasil do Segundo Império e da República.

Sua obra é vasta e variada - por volta de cinquenta volumes - e se faz presente em todos os gêneros: poesia, teatro, romances e contos, crítica 
literária, crônicas de jornal. A extensão de sua obra se deve, principalmente, a essas duas últimas rubricas, nas quais, mesmo sendo escritos de circunstância, também afloram suas qualidades de escritor. Entretanto, a fonte de sua notoriedade se encontra em quatro romances e algumas dezenas de contos. Essa notoriedade se deve, talvez, ao fato de ele ser o único autor brasileiro que, mesmo pintando um quadro da sociedade de seu tempo, soube atingir o universal, termo que tomamos no sentido dos problemas essenciais colocados pelo destino do homem: a vida e a morte, a razão e a loucura, o amor, o bem e o mal. Tais categorias, no entanto, não exprimem com suficiente fidelidade a complexidade de sua criação. Se ele é sempre o escritor hábil que sabe encontrar a forma exata correspondente ao pensamento ou ao sentimento que quer expressar e, por essa razão, deve ser incluído entre os escritores "clássicos", sua singularidade, entretanto, reside sobretudo na visão de homem, tanto irônica quanto desabusada, que ele propõe em seus romances e contos.

Por este último aspecto, ele interessa ao comparatista. Com efeito, sua criação se apoia em um conhecimento profundo da cultura europeia. As elites brasileiras do século XIX eram bastante cultas e a cultura europeia exercia sobre elas tal fascínio que, por vezes, freava o elã criador dos escritores. Machado de Assis, que era de origem muito humilde, pois seu bisavô fora escravo, já havia ascendido os degraus da escala social brasileira. No entanto, a relativa pobreza de seus pais o impediu de ir além dos estudos primários. A cultura por ele adquirida corresponde, portanto, em sua maior parte, ao contato de uma inteligência viva com o patrimônio comum oferecido pela leitura dos grandes escritores. Ele bebe das melhores fontes como testemunha, entre outras coisas, sua biblioteca ${ }^{1}$ - e assimila a herança do passado, que fecunda sua criação. É certo que, como ocorre com todo jovem escritor, o fascínio exercido pela cultura o impede, durante algum tempo, de criar uma obra verdadeiramente original. Como todos, ele fazia sua lição de casa. No entanto, graças a seus dons, Machado de Assis rapidamente remedeia os inconvenientes de sua condição de relativo autodidata, evitando os dois excessos comuns ao Oitocentos hispanoamericano: o da alienação pela assimilação e o da revolta pelo indianismo. Por volta de 1870, quando ele ainda está na casa dos trinta anos, a balança começa a pender a seu favor. Ele começa a produzir, com aparente

${ }^{1}$ MASSA, "La Bibliothèque de Machado de Assis". 
facilidade, uma obra pessoal na qual a contribuição da cultura estrangeira se alia e se harmoniza a sua criação original. Seu exemplo mostra que a justa medida não é necessariamente sinônimo de mediocridade.

O comparatista poderia estudar, com proveito e sucesso, a presença, na obra de Machado de Assis, de Shakespeare, Swift, Sterne, Dickens, a de Goethe, Schiller ou Heine, e, no que diz respeito ao domínio francês, a maior parte de seus escritores, sobretudo os do século XIX. Esse trabalho se voltaria inicialmente para as traduções por ele realizadas de alguns dos escritores citados; em seguida, para a presença da obra desses escritores em seus romances e seus contos; e, por fim, para a maneira pela qual ele assimilou essas obras. Sabemos que o cordeiro devorado pelo lobo se transforma em leão.

Voltemos aos nossos carneiros; no caso, a Dante. Para estudá-lo, quatro frentes de investigações são necessárias, segundo, mais ou menos, a ordem que se segue.

1. Estudo das citações de Dante na obra de Machado de Assis.

2. Análise de uma tradução feita pelo brasileiro.

3. Busca das alusões à obra do florentino que não se apoiam em referência direta ao textual.

4. Impulso dado à obra de Machado de Assis pela técnica ou poesia do italiano.

Abordaremos os dois primeiros pontos: o estudo de umas duas dezenas de citações e a tradução do canto XXV do "Inferno". Desse modo, veremos apenas o que transparece do conhecimento de Dante, a presença de Dante, o Dante de Machado de Assis. Deixaremos de lado, por ora, o aspecto mais dinâmico, a influência do poeta sobre a criação literária de Machado de Assis e o eco da leitura de Dante na obra do brasileiro.

Nossa reflexão foi auxiliada por uma pequena obra de umas trinta páginas, Machado de Assis e a Itália, publicada pelo diretor do Instituto Italiano de São Paulo, Edoardo Bizzarri. ${ }^{2} \mathrm{O}$ autor aborda um tema muito mais amplo do que o nosso, mas dedica cinco páginas a Dante e Machado de Assis. Faz um inventário bastante completo das citações de Dante e dá início ao estudo do problema. Adicionem-se a isso algumas reflexões de Mário de

2 BIZZARI, Machado de Assis e a Itália. 
Andrade, ${ }^{3}$ uma dezena de breves comentários de Agripino Grieco, ${ }^{4}$ e esgotase a bibliografia dedicada ao assunto.

Desde sua adolescência, Machado de Assis conhece o italiano. A audição da ópera italiana no Rio ao menos deve ter preparado seu ouvido. Não se sabe nem onde nem como ele aprendeu essa língua. Descobriu-se, no entanto, que, em 1859, aos vinte anos, ele havia traduzido uma ópera italiana para o português..$^{5}$ A leitura de Dante parece ser bem posterior a essa data.

Antes de 1873 só encontramos na obra de Machado de Assis uma epígrafe tirada da Vita nova: "tacendo il nome di questa gentilissima". ${ }^{6}$ Essa referência abre um poema datado de $1864 .{ }^{7} \mathrm{Na}$ época, era frequente entre os poetas tomar epígrafes emprestadas a algum colega. Ainda que não tenhamos localizado essa frase na obra de um escritor ou de um poeta que ele pudesse haver lido naquele momento, aceitamos essa hipótese. Se ele tivesse lido a Vita nova, sem dúvida encontraríamos outros ecos dessa leitura. Prova definitiva de sua ignorância: nesse mesmo poema, quando ele evoca Beatriz, a chama "flor e honra do Latium".*

Por outro lado, a partir de 1873, ele cita Dante com bastante frequência, mas exclusivamente a Divina Comédia. Contam-se vinte citações: oito nos romances ou contos, doze nas crônicas. ${ }^{8}$ Três vêm do "Purgatório", dezessete do "Inferno". Trata-se evidentemente de citações diretas feitas em italiano. A descoberta e a leitura da Divina Comédia situam-se, aparentemente, por volta de $1873 .{ }^{9}$ De resto todas as citações são posteriores a essa data. Em 1874,

\footnotetext{
${ }^{3}$ ANDRADE, Aspectos da literatura brasileira, pp. 89-108.

${ }^{4}$ GRIECO, Machado de Assis, passim.

5 Trata-se da ópera Pipelé, dos Mystères de Paris. O libreto havia sido escrito em italiano.

${ }^{6}$ Vita Nova, XXIII.

7 "Versos a Corina", poema republicado em Crisálidas (1864).

*Verso excluído na edição das Poesias completas, de 1901. Nas Crisálidas aparece "Lácio", não Latium (Nota dos tradutores).

8 Citamos os textos de Machado de Assis segundo a numeração feita por José Galante de Souza na Bibliografia de Machado de Assis. Ao lado damos as referências das citações da Divina Comédia. 448. (I.V. 121) - 452. (I.III.1) - 448. (1. V. 121) - 452. (1.III. 1) - 489. (1. 1. 3) - 505. (1. XXV. 144-145) - 553. (1. XX. 23-24) - 573. (1. III. 51) - 596. (1. XXXIII. 1-2) - 926. (1. III. 9) - 1033. (1. V. 4647) - 1128. (1. III. 4951) - 1164. (I. III. 7 et I. V. 81) - 1187. (Il. XXXIII. 143-144) - 1205. (1. V. 118, 1. V. 120 et 1. V. 135) - 1208. (II. XXXIII. 143-144) - 1253. (I. V. 7) - 1268. (Il. V. 133 et 1. V. 93). Esses textos correspondem às obras publicadas em: 1873, 1874, 1876, 1877, 1878, 1879, 1881, 1889, 1893, 1895, 1896, 1896, 1896, 1896, 1903, 1907.

${ }^{9}$ Em um conto de juventude, datado de 1867, "Francisca", e republicado nos Contos recolhidos, por R. Magalhães Jr., o nome da heroína dantesca não é pronunciado, ainda que o autor, para definir sua personagem, a aproxime de Ruth, de Virgínia e de Ofélia. Podemos tirar inúmeras conclusões desse
} 
traduziu um episódio da Divina Comédia. Não há dúvida de que ele utilizou a edição Firmin Didot (1868) que figura em sua biblioteca.

A exemplo dos românticos franceses, os brasileiros apreciavam Dante. $\mathrm{Na}$ França, como M. Pézard mostrou, os escritores mais o admiravam que o conheciam de fato. ${ }^{10} \mathrm{O}$ mesmo acontece no Brasil. Ele é vestido com as cores da época. Quando é citado, é a partir de traduções francesas, salvo por Gonçalves Dias, que, de resto, assinou uma tradução pouco fiel do episódio de Sordello. ${ }^{11 *}$ Um certo Vialli publicou uma passagem da Divina Comédia em uma revista. ${ }^{12}$ É comum colocar o nome de Dante ao lado dos de Shakespeare e de Calderón, autores que, depois de Schlegel, são considerados "românticos". Desse modo, Dante aparece bastante frequentemente, mas na maior parte das vezes de maneira pouco precisa. Salvo pela descoberta de algum documento importante que nos teria escapado, podemos afirmar que, durante o romantismo brasileiro, e pelos decênios que se seguem, Dante era ilustre e pouco conhecido.

O interesse a ele consagrado por Machado de Assis, além de sinal de sua cultura e curiosidade intelectual, representa uma inovação. Ele não parece ter sido diretamente influenciado pelos numerosos estudos publicados na França e na Itália e que lhe teriam permitido melhor conhecêlo. Trata-se sobretudo do resultado de uma escolha pessoal, ainda que o renome do Florentino tenha se propagado até as plagas americanas.

Vimos que, das vinte citações, dezessete vêm do "Inferno", três do "Purgatório". Machado de Assis se limita, portanto, nessas citações, aos dois primeiros reinos. Reencontramos episódios clássicos do romantismo: a chegada ao Inferno, a entrada na Città de Dite, Francesca da Rimini, Ugolino. Passagens às quais Machado de Assis foi levado pela nova aura a elas atribuída pelos românticos.

\footnotetext{
fato. Parece pouco provável que, mesmo sem ter lido a Divina Comédia, Machado de Assis ignore o nome de Francesca da Rimini. Apreciador de alusões literárias, em um conto de amor que se prestasse a isso, a referência seria natural. Mas esse conto talvez seja apócrifo. Assinado por um pseudônimo, Máximo, foi publicado no Jornal das Famílias, revista com a qual colaborava Machado de Assis. Entretanto, a autenticidade não é certa e era comum o editor R. Magalhães Jr. fazer atribuições abusivas.

10 PEZARD, Comment Dante conquit la France aux beaux jours du Romantisme.

${ }^{11}$ DIAS, Obras, p. 671-673.

* Refere-se ao canto VI do "Purgatório" (Nota dos tradutores).

12 Guanabara, Rio de Janeiro, set. 1854.
} 
Passagens das quais ele se serve, seja em suas obras românticas, seja em suas crônicas, para ilustrar uma situação ou concluir um assunto. Eis dois exemplos: no romance $A$ mão e a luva, a propósito das dificuldades que Estevão experimenta em sua conquista amorosa, ele afirma: "aquela porta fechada, que bem podia ser a da città dolente". ${ }^{13}$ Em uma crônica, ${ }^{14}$ ao evocar sua própria juventude, relembra os tempos dos dolci sospiri e aqueles dos dubbiosi desiri. Não há nada de excepcional aqui, a não ser a citação direta. $\mathrm{O}$ Dante de Machado de Assis é, portanto, o Dante dos românticos.

Entretanto, a escolha de certas passagens mostra que seu interesse não se limitava aos tópicos tradicionais.

Em outra crônica, ${ }^{15}$ na qual fala de mágicos, sabe encontrar o canto da Divina Comédia que evoca os indovini. Machado de Assis ilustra seu tema por dois versos do canto XX do "Inferno":

... che' l pianto degli occhi

le natiche bagnava per lo fesso.

Por várias vezes modifica o texto do escritor italiano. Em uma advertência aos políticos de seu tempo, escreve ironicamente: ${ }^{16}$

Servate ogni speranza voi ch'entrate.

Um personagem de um de seus contos se despede de um sujeito maçante transformando os versos que abrem o canto do Ugolino: ${ }^{17}$

\section{La bocca sollevò dal fiero pasto}

quel 'seccatore'.

Assim se confirma o interesse do escritor pela Divina Comédia. Ele frequenta a obra, faz dela uma leitura pessoal que se revela, quando se apresenta a ocasião, numa ou noutra de suas obras. Aparentemente, nenhum outro escritor brasileiro manteve tal contato direto, ao menos, não neste

\footnotetext{
13 453. A mão e a luva (1874), capítulo 6.

${ }^{14} 1205$. (1 ${ }^{\circ}$ nov. 1896$)$.

15 19/5.9/59/53 (1 ${ }^{\circ}$ jan. 1877).

16 926. (13 jan. 1889).

${ }^{17}$ 596. O alienista (1881).
} 
grau. Para além desta presença de Dante, uma influência implícita pode ser confirmada pelo estudo de um bom número de textos de Machado de Assis. Pelo que não podemos subscrever a afirmação de Agripino Grieco: "Talvez ele não conhecesse os escritores italianos, e especialmente Dante, corretamente citado por ele, melhor do que aos ingleses". ${ }^{18}$

Essa curiosidade a respeito de Dante e da Divina Comédia parece chegar ao ápice em 1874. É então que ele traduz o canto XXV do "Inferno".

Em seus poemas, Machado fez algumas tentativas em terza rima. A respeito de um deles, "Última jornada", Mário de Andrade, que acertadamente nele encontra uma influência direta do canto V do "Inferno", afirma: "Não me lembro, por ora, que os escritores românticos a tenham praticado uma única vez". ${ }^{19}$ Sua memória o enganou. Machado de Assis não é o introdutor da terza rima no Brasil. Já em 1830, Gonçalves de Magalhães a empregara em uma elegia. ${ }^{20} \mathrm{E}$, em 1851, Gonçalves Dias utilizou essa forma métrica em "Sei amar". 21

Ao ler a obra de seus predecessores, Machado de Assis pôde conhecer a terza rima antes de descobrir a Divina Comédia. O que é confirmado pela data de "No limiar" (1863), escrita em terza rima. Ele ainda se servirá dessa métrica em 1900 em um poema comemorativo, "José de Anchieta". A originalidade de Machado de Assis se encontra em outro lugar, na "Dantologia" do Brasil. Ela consiste na escolha de um episódio da Divina Comédia, não apenas pouco conhecido, mas também pouco apreciado: o canto dos ladrões situado no âmago do "Inferno".

Por um artigo de M. Pézard, já citado, e pelo estudo de Aldo Vallone, ${ }^{22}$ conhecemos o Dante que o século XIX definiu e ama, tanto na Itália como na França. Do outro lado dos Alpes, ele permanece constantemente ligado ao Risorgimento. Estudam-se preferencialmente o homem, o patriota, o italiano, o teórico da Itália, com uma visão controversa, mas sempre ligada aos problemas de política ou de filosofia política. A crítica francesa de Villemain e Fauriel a Ozanam, com alguma divergência, segue esse movimento ou o reencontra. Por meio da obra se define o homem inflamado que viveu um

\footnotetext{
${ }^{18}$ GRIECO, cit., p. 135.

${ }^{19}$ ANDRADE, cit., p. 101.

${ }^{20}$ MAGALHÃES, Elegia à morte do exímio orador Fr. Francisco de Sampaio (1830).

${ }^{21}$ DIAS, cit., p. 418. Ela se encontra na coletânea Últimos cantos (1851).

22 VALLONE, La critica dantesca nell'Ottocento.
} 
certo momento histórico. Ainda que simplificado aqui ao extremo, nossa apresentação pouco altera o rosto que se dá a Dante há já um século.

Com uma intuição certeira ou, para ser mais exato, com um gosto que corresponde ao de nossa época, Machado de Assis escolheu, entre os cem cantos, aquele marcado de uma poesia inabitual, que ele descobre e dá a descobrir ao Brasil. Traduzir, nesse caso, é, também, escolher. No século XIX, que eu saiba, nenhum comentador italiano ou francês concedeu qualquer particularidade a esse canto ou mesmo sublinhou qualquer interesse que ele pudesse apresentar. Nem mesmo Foscolo, que, como poeta, percebeu certos aspectos sutis da obra de Dante. Apenas em 1870, mas para condenar os excessos do poeta, De Sanctis se interessou por ele, em seu estudo global da Comédia, que faz parte de sua História da literatura italiana - texto que Machado de Assis pôde ler mais tarde. "Vi è il descrittivo, manca il drammatico", ${ }^{23}$ ele afirma sobre essa última parte dos Malebolge. De Sanctis aprecia a facilidade de Dante e sua viva imaginação; no entanto, seu julgamento estético é desfavorável: "Il più grande sforzo della immaginazione umana è la trasformazione di uomini in bestie nel canto XXV, quantunque la soverchia minutezza generi saziet $\dot{a}^{\prime \prime}{ }^{24 *}$

O canto traduzido por Machado de Assis evidentemente está isolado de seu contexto e especialmente do canto XXIV, com o qual ele forma um conjunto. Por essa razão não parece que Machado de Assis estivesse especialmente interessado na figura de Vanni Fucci, que, cortado em dois, sofre um tal suplício que nem mesmo Dante o teria imaginado para si próprio. Também não é especificamente para este suplício dos ladrões - a encarnação do mal entre os malfeitores - que Machado de Assis quer chamar nossa atenção, mas sobretudo para a descrição das transformações do ladrão em serpente e vice-versa. Lembramos que essa metamorfose, uma vez que Vanni Fucci se volatiza, ocupa quase todo o canto.

Ele deve ter ficado maravilhado diante da proeza realizada por Dante na descrição dessas mudanças sucessivas, com motivos plásticos e esculturais. Mas por que isto justificaria tal escolha? Se Machado de Assis não é discípulo do Parnaso, nem por isso ele é insensível à "contemplação serena das formas divinas" preconizadas por Leconte de Lisle. Diga-se de

\footnotetext{
23 "Aqui tem-se o descritivo, falta o dramático." (Nota dos tradutores).

${ }^{24}$ DE SANCTIS, Storia della letteratura italiana, vol. I, p. 205.

* "O grande esforço da imaginação humana no canto XXV serve à transformação de homens em animais, ainda que a abundante pormenorização leve à saturação" (Nota dos tradutores).
} 
passagem que a influência dos parnasianos sobre a obra de Machado de Assis é ainda um terreno de estudos virgem, mesmo que, à sua maneira, entre 1870 e 1880, ele tenha buscado certa perfeição formal em seus poemas. Essa escolha do canto XXV, por paradoxal que tal afirmação possa parecer, não seria uma homenagem à Beleza? Momigliano, em seu célebre comentário, evoca Michelangelo. Talvez esse canto tenha interessado ao poeta brasileiro pelo estudo escultural e plástico que, para ele, o canto possa ter evocado. A seu modo, Machado de Assis colocou Dante ao gosto da época ou, mais exatamente, a parte de sua sensibilidade despertada pelas obras parnasianas reencontrou no poeta florentino acentos comparáveis. Esta descoberta é tanto mais meritória uma vez que Dante, que não era nem grego nem hindu, não era apreciado pelos parnasianos. De todo modo, esta explicação é proposta apenas a título de hipótese pois, na falta da confissão do tradutor, permanece difícil apreciar todos os motivos de sua escolha.

Não incluímos nessas observações a análise da tradução realizada por Machado de Assis, que reservamos para outro trabalho. ${ }^{25}$

Por essa razão e também porque abordamos apenas dois aspectos dos diversos problemas apontados, não é possível trazer uma conclusão digna desse nome a esse estudo da presença de Dante na obra de Machado de Assis. O campo permanece aberto. Foram lançadas apenas algumas balizas. Nada mais do que uma pequena parte do que resta a descobrir nesse vasto domínio ainda pouco explorado do contato entre a Itália e o mundo lusobrasileiro. $^{26}$

\section{Referências}

ANDRADE, Mário de. Aspectos da literatura brasileira [1939]. São Paulo: Livraria Martins Editora, s.d., p. 89-108.

BIZZARI, Edoardo. Machado de Assis e a Itália. São Paulo: Instituto Cultural ÍtaloBrasileiro, 1961, Caderno 1.

${ }^{25}$ Machado de Assis traducteur.

${ }^{26}$ Comunicação feita em 27 de maio de 1965 no Sétimo Congresso Nacional da Société Française de Littérature Comparée. Posteriormente tivemos conhecimento de um número especial dedicado a Dante pelo Suplemento Literário do Estado de S. Paulo, n. 430, 22 maio 1965. Nele tratou-se apenas acessoriamente do problema que nos interessa. 
DE SANCTIS, Francesco. Storia della letteratura italiana. Napóles: Morano, 1912, vol. I.

DIAS, Gonçalves. Obras. Rio de Janeiro: Aguilar, s.d.

GRIECO, Agripino. Machado de Assis. Rio de Janeiro: José Olympio, 1959.

GUANABARA, Rio de Janeiro, set. 1854.

MAGALHÃES JR., R. (Org. e prefácio). Contos recolhidos [de Machado de Assis]. Rio de Janeiro: Civilização Brasileira, 1956.

MASSA, Jean-Michel. La Bibliothèque de Machado de Assis. Revista do Livro, n. 2122, mar.-jun. 1961, p. 195-238.

- Machado de Assis: traducteur. Paris, Faculté des Lettres de Poitiers, 1970 [Ed. bras.: Machado de Assis tradutor. Belo Horizonte: Crisálida, 2008].

NÚMERO especial dedicado a Dante. Estado de S. Paulo, Suplemento Literário, n. 430, 22 maio 1965.

PEZARD, A. Comment Dante conquit la France aux beaux jours du Romantisme. In: Studi in onore de Carlo Pellegrini. Turim: Società Editrice Internazionale, 1963, p. 683-706.

SOUZA, José Galante de. Bibliografia de Machado de Assis. Rio de Janeiro: INL, 1955.

VALLONE, Aldo. La critica dantesca nell'Ottocento. Firenze: Olschki, 1958.

JEAN-MICHEL MASSA (Paris, 1930 - Paris, 2012) foi professor emérito da Universidade de Rennes 2, França. Publicou diversos artigos e livros, como Dispersos de Machado de Assis (Rio de Janeiro: Instituto Nacional do Livro, 1965), La jeunesse de Machado de Assis (1839-1870): essai de biographie intellectuelle, 1969 (A juventude de Machado de Assis, 1839-1870: ensaio de biografia intelectual. 2. ed. São Paulo: Editora da Unesp, 2009), Machado de Assis: traducteur, 1970 (Machado de Assis tradutor. Belo Horizonte: Crisálida, 2008). 